\title{
Intellectual Test System for Internal Combustion Engines
}

\author{
${ }^{1}$ Lenar A. Galiullin, ${ }^{2}$ Shafik Sh. Khuzyatov \\ 1-2 Kazan Federal University \\ Email: galilenar@yandex.ru
}

\author{
Received: 23 ${ }^{\text {rd }}$ July 2019, Accepted: 10 $^{\text {th }}$ August 2019, Published: $3^{\text {st }}$ August 2019
}

\begin{abstract}
An integral part of the complex process of creating, improving and producing internal combustion engines are testing them. This is explained by the fact that only during testing you can determine the overall technical and economic efficiency of the engine created or upgraded, the actual loads on its parts and assemblies, as well as the correctness of the production technology of serial engines. Mathematical models of engines based on differential equations, tabular structure and artificial intelligence are considered. Among the methods of artificial intelligence highlighted fuzzy logic, allowing better describe the process of controlling the internal combustion engine. The object of control is a test bench with an installed engine and technological equipment, providing testing. Depending on the type of testing, the composition of the equipment interacting with system and the technology of testing can vary. Tests are among the most responsible and time-consuming stages of the life cycle of the engine. At this stage, the final assessment of the structure is carried out, its compliance with technical and technological requirements is determined.
\end{abstract}

\section{Keywords}

Linguistic Variables; Engine; Neural Network; Fuzzy Logic; Test.

\section{Introduction}

The complexity of the engine management systems in recent years has increased significantly - both due to the tightening of environmental standards and requirements for reducing fuel consumption, and due to forcing engines [1]. Despite the fact that there are only two main control parameters - fuel supply and external load, however, the control system operates in real time, therefore, it is advisable to control based on a mathematical model [2]. The full mathematical model of the ICE is too complicated and has not yet been created [3]. Because of this, most engine management systems use a model built on the basis of differential equations [4]. A serious disadvantage of such a model is the complexity of its creation and high error [5].

The use of fuzzy logic in an automated test system (ATS) of an internal combustion engine allows you to control the required test accuracy based on the number of control rules [6]. The more of them, the higher the accuracy, but it requires more ATS computing resources [7].

The relevance of the topic is due to the need to automate the engine management function in the process of bench testing - a mass technological operation at the stage of putting the product into operation [8].

\section{Methods}

ATS, built on the basis of fuzzy logic, allows to improve the quality and efficiency of design development, to reduce the time of refinement and improvement of engines while reducing the cost of bench testing [9].

The knowledge base of the fuzzy controller has been developed, and methods for its filling are also considered [10]. A sequence of stages for creating tests has been developed [11].

In the test image creation block, the user creates a sequence of changes of parameters of interest from time, which are recorded in the block "database of images and programs - tests" [12]. In this multi-level database, the input images are sequentially transformed into control actions by means of a fuzzy controller, which is located in the "test program generation" block [13]. To obtain output values, a fuzzy controller uses fuzzy rules that are located in the "knowledge base" block [14]. As a result, a sequence of control parameters is formed, which is stored in the "database of images and test programs" [15]. On the basis of the resulting data, the "control unit" performs direct testing. In the process of testing using the "sensor unit" we obtain information about the current position of the object [16]. All this data is stored in the "information storage" unit [17].

The "learning unit" can control the "control unit" and receive information from the sensors in feedback mode [18]. This is necessary in order to fill the knowledge base, on the basis of which the control rules are formed [19]. These rules can also be created or adjusted based on the information that comes from the "control history storage unit" to the training unit [20].

The knowledge base of a fuzzy controller consists of three levels. The first level contains the linguistic variables used for phasing data. Linguistic variables are populated by experts in the field and direct measurement methods. At this level, the base range and the number of fuzzy marks (FMs) on it are determined, as well as the type of the membership function. The number of FM depends on the accuracy of control.

At the second level, the fuzzy control rules are used, which are used to convert the specified parameters into control ones. These rules are made up of linguistic variables defined in the level above.

At the third level, priority vectors are located to rank the characteristics. Priority vectors consist of specified parameters. 
On their basis, you can set a certain direction to the tests.

During the tests in the ATS used feedback. It is used not only to record the results, but also to fill the knowledge base using the precedent method.

The process of creating a test engine is the following sequence of steps.

The upper level is a technique - test. It is developed by the technologist taking into account the engine parameters of interest to him.

This method - testing technologist implements in the form of images specifying parameters. The next step is to convert images into a pivot table of parameters. To do this, all the time of the test is divided into time intervals $t_{\text {min }}$, at which the internal combustion engine will be controlled. The choice of these values should be as small as possible, since this leads to an increase in control accuracy and the elimination of emergency modes, but as the intervals decrease, the required computer resources increase. Based on these values, the number of points at which control will be performed during the test is determined [21].

Then, for each time interval, the values of the measured parameters $\left(A_{1 i}, A_{2 i}, A_{3 i}, \ldots, A_{m i}\right)$ are determined, where $A_{\mathrm{i}}$ is the value of the parameter at a certain point in time, which is obtained from the corresponding $m$ images. This data is stored in the summary table of parameters presented in Table 1.

\begin{tabular}{|c|c|c|c|c|c|c|}
\hline № & Test time & Form 1 & Form 2 & Form 3 & $\ldots$ & Form $\mathrm{m}$ \\
\hline 1 & $\mathrm{t}=0$ & $\mathrm{~A}_{11}$ & $\mathrm{~A}_{21}$ & $\mathrm{~A}_{31}$ & $\ldots$ & $\mathrm{A}_{\mathrm{m} 1}$ \\
\hline 2 & $\mathrm{t}=\mathrm{t}_{\min }$ & $\mathrm{A}_{12}$ & $\mathrm{~A}_{22}$ & $\mathrm{~A}_{32}$ & $\ldots$ & $\mathrm{A}_{\mathrm{m} 2}$ \\
\hline 3 & $\mathrm{t}=\mathrm{t}+\mathrm{t}_{\min }$ & $\mathrm{A}_{13}$ & $\mathrm{~A}_{23}$ & $\mathrm{~A}_{33}$ & $\ldots$ & $\mathrm{A}_{\mathrm{m} 3}$ \\
\hline & $\ldots$ & $\ldots$ & $\ldots$ & $\ldots$ & $\ldots$ & $\ldots$ \\
\hline $\mathrm{S}$ & $\mathrm{t}_{\mathrm{is}}$ & $\mathrm{A}_{1 \mathrm{~S}}$ & $\mathrm{~A}_{2 \mathrm{~S}}$ & $\mathrm{~A}_{3 \mathrm{~S}}$ & $\ldots$ & $\mathrm{A}_{\mathrm{mS}}$ \\
\hline
\end{tabular}

Table 1: Summary Table of Parameters

At the next stage, fuzzification is performed, that is, the conversion of the clear values of the input variables $A_{i}$ into fuzzy $B_{i}$ by means of a linguistic variable. Such a transformation is actually a kind of rationing necessary to translate the given data into subjective evaluations. Linguistic variables for translating a clear value into a fuzzy are stored in a fuzzy logic knowledge base [22]. The result of the work at this stage will be a converted summary table of parameters, in which fuzzy labels will be placed for clear values, in general, the result of this stage will be presented in Table 2.

\begin{tabular}{|c|c|c|c|c|c|c|}
\hline № & Test time & FL of Form 1 & FL of Form 2 & FL of Form 3 & $\ldots$ & FL of Form $m$ \\
\hline 1 & $\mathrm{t}=0$ & B11 & B21 & B31 & $\ldots$ & Bm1 \\
\hline 2 & $\mathrm{t}=\mathrm{tmin}$ & B12 & B22 & B32 & $\ldots$ & Bm2 \\
\hline 3 & $\mathrm{t}=\mathrm{t}+\mathrm{tmin}$ & B13 & B23 & B33 & $\ldots$ & Bm3 \\
\hline & $\ldots$ & $\ldots$ & B2S & B3S & $\ldots$ & $\ldots$ \\
\hline $\mathrm{S}$ & $\mathrm{t}$ & B1S & $\ldots$ & $\ldots$ & BmS \\
\hline
\end{tabular}

Table 2: Fuzzy Input Parameters

The next stage is the formation in the output unit of an approximate fuzzy result. To do this, apply fuzzy rules that are stored in the knowledge base of fuzzy logic [23]. On the basis of these rules, a fuzzy control table is formed, which is presented in Table 3.

\begin{tabular}{|c|c|c|c|c|c|c|}
\hline № & Test time & FL of Form 1 control & FL of Form 2 contro & FL of Form 3 control & $\ldots$ & FL of Form k control \\
\hline 1 & $\mathrm{t}=0$ & $\mathrm{C} 11$ & $\mathrm{C} 21$ & $\mathrm{C} 31$ & $\ldots$ & Cm1 \\
\hline 2 & $\mathrm{t}=\mathrm{tmin}$ & $\mathrm{C} 12$ & $\mathrm{C} 22$ & $\mathrm{C} 32$ & $\ldots$ & $\mathrm{Cm} 2$ \\
\hline 3 & $\mathrm{t}=\mathrm{t}+\mathrm{tmin}$ & $\mathrm{C} 13$ & $\mathrm{C} 23$ & $\mathrm{C} 33$ & $\ldots$ & $\mathrm{Cm} 3$ \\
\hline & $\ldots$ & $\ldots$ & $\ldots$ & $\ldots$ & $\ldots$ & $\ldots$ \\
\hline $\mathrm{S}$ & $\mathrm{tis}$ & $\mathrm{C} 1 \mathrm{~S}$ & $\mathrm{C} 2 \mathrm{~S}$ & $\mathrm{C} 3 \mathrm{~S}$ & $\ldots$ & CmS \\
\hline
\end{tabular}

Table 3: Fuzzy Output Parameters

The next stage is defuzzification [24]. Defuzzification is the process of converting fuzzy values resulting from fuzzy output into clear ones, on the basis of which the engine can be tested. The result of this stage is presented in table 4.

\begin{tabular}{|c|c|c|c|c|c|c|}
\hline $\begin{array}{c}\text { № } \\
\Pi / \Pi\end{array}$ & $\begin{array}{c}\text { Test } \\
\text { time }\end{array}$ & $\begin{array}{c}\text { Exact control value } \\
1\end{array}$ & $\begin{array}{c}\text { Exact control value } \\
2\end{array}$ & $\begin{array}{c}\text { Exact control value } \\
3\end{array}$ & $\begin{array}{c}\text { Exact control value } \\
\mathrm{j}\end{array}$ \\
\hline 1 & $\mathrm{t}=0$ & $\mathrm{f} 11$ & $\mathrm{f} 21$ & $\mathrm{f} 31$ & $\ldots$ & $\mathrm{fk} 1$ \\
\hline 2 & $\mathrm{f}=\mathrm{tmin}$ & $\mathrm{f} 12$ & $\mathrm{f} 22$ & $\mathrm{f} 32$ & $\ldots$ & $\mathrm{fk} 2$ \\
\hline 3 & $\begin{array}{c}\mathrm{t}=\mathrm{t}+ \\
\mathrm{tmin}\end{array}$ & $\mathrm{f} 13$ & $\mathrm{f} 23$ & $\mathrm{f} 33$ & $\ldots$ & $\mathrm{fk} 3$ \\
\hline & $\ldots$ & $\ldots$ & $\ldots$ & $\ldots$ & $\ldots$ & $\ldots$ \\
\hline $\mathrm{S}$ & $\mathrm{t}$ tis & $\mathrm{f} 1 \mathrm{~s}$ & $\mathrm{f} 2 \mathrm{~s}$ & $\mathrm{f3s}$ & $\ldots$ & $\mathrm{fks}$ \\
\hline
\end{tabular}

Table 4: Exact Control Values

\section{Results and Discussion}

Using this knowledge base, a control program is developed in accordance with GOST 18509-88, a ranking of control values is developed based on the method of pairwise comparisons [25].

Fuzzy inference systems are built on the basis of the concepts of a linguistic variable consisting of five objects [26]: 
$<X, U, T(x), G, S>$

where $X$ is the proper name of the variable; $U$ is the base set; $T(x)$ - fuzzy labels; $G$ - syntactic rules of control; $S$ semantic rules of control.

As $X$, all the control and setting parameters are selected, for example, the position of the pump regulator $L$, the crankshaft speed $n$, the torque $M_{H}$, the fuel consumption $G_{T}$.

The base set $U$ is the range of possible values of $X$. These parameters depend on the characteristics of the control object: $L$ from 0 to $50 \mathrm{~mm}, n$ from 600 до $2450 \mathrm{rpm}, M_{H}$ from 73 to $126 \mathrm{Nm}, G_{T}$ from 18,6 to 59,4 g.

Fuzzy labels $T(x)$ are located on the base set. The connection between $U$ and $T(x)$ is carried out using membership functions (MF). The main MFs used are the triangular function and the Gaussian distribution. In the linguistic variables $L, n, M_{H}, G_{T}$ under consideration, a larger range of values constitute linear dependencies; as a result, the triangular distribution function is chosen, since it describes the linear segments better. Analytically, a triangular MF can be specified as follows:

$$
\mu(x, a, b, c)=\left\{\begin{array}{l}
0, x<a, \\
\frac{x-a}{b-a}, a \leq x \leq b, \\
\frac{c-x}{c-b}, b \leq x \leq c, \\
0, x>c,
\end{array}\right.
$$

where $x$ is the base value;

$$
\begin{aligned}
& b-\text { a fuzzy label corresponding to the top of the distribution; } \\
& a-\text { is the left boundary of the membership function; } \\
& c-\text { is the right boundary of the membership function; } \\
& \mu(x, a, b, c) \text { - triangular membership function. }
\end{aligned}
$$

When compiling $T(x)$, it is necessary to determine the number of fuzzy marks. The more of them, the more accurate the control is, but the dimension of the knowledge base increases, which leads to an increase in the time it is filled.

First of all, linguistic variables are determined that can be controlled and, accordingly, know exactly their meaning during the experiment. Such a linguistic variable is the position of the fuel pump regulator $L$. To obtain the required accuracy, we divide this basic value of this parameter into eleven fuzzy marks $(0,5,10 \ldots 50)$.

The characteristics of the linguistic variables $n, M_{H}, G_{T}$ directly depend on the position of the pump regulator $L$ and, therefore, are also divided into 11 fuzzy labels.

To find the values of linguistic variables $n, M_{H}, G_{T}$ the engines 740-30-260 were tested at the engine testing station of Kamaz-Diesel. During the tests, the regulator was controlled with a fixed external load of $10 \mathrm{Nm}$. Measurements of revolutions and load moment were made at the time point corresponding to their indistinct marks $L$. Ten engines participated in the tests, the arithmetic-mean results of their parameters are listed in Table 5.

\begin{tabular}{|l|c|c|c|c|c|c|c|c|c|c|c|}
\hline $\mathrm{L}, \mathrm{mm}$ & 0 & 5 & 10 & 15 & 20 & 25 & 30 & 35 & 40 & 45 & 50 \\
\hline $\mathrm{n}, \mathrm{rpm}$ & 600 & 935 & 1155 & 1355 & 1555 & 1760 & 1960 & 2165 & 2340 & 2425 & 2450 \\
\hline$M_{H}, \mathrm{Nm}$ & 73 & 101 & 120 & 126 & 125 & 118 & 113 & 111 & 110 & 110 & 110 \\
\hline$G_{T}, \mathrm{~g}$ & 18,60 & 23,10 & 29,50 & 35,90 & 41,80 & 46,90 & 50,80 & 54,20 & 57,10 & 58,90 & 59,40 \\
\hline
\end{tabular}

\section{Table 5: Test Results}

Based on the test results, the linguistic variables $n, M_{H}, G_{T}$ are presented.

The syntactic and semantic rules $G(x)$ and $S(x)$. are superimposed on these linguistic variables. The syntax rules determine the order in which the base values are generated relative to time. For example, it is impossible to accelerate to the maximum speed from the minimum rpm and vice versa, if we sharply stop the engine at the maximum rpm, this can lead to its failure. Semantic rules, in turn, determine the influence of linguistic variables on each other. For example, at a given minimum speed it is not possible to get the maximum power or torque. These rules also allow to exclude emergency modes.

\section{Summary}

The parameters $n, M_{H}, G_{T}$ have a different effect on the final result depending on the type of tests performed. For ranking effects, apply the pair-comparison method.

We will create a matrix of pairwise comparisons for the linguistic variables $N, M_{H}$, $G_{T}$, in which we will place more weight on the parameters $\mathrm{N}$ and $\mathrm{R}$, since the tests are aimed at the efficiency of the engine, table 6 . 


\begin{tabular}{|c|c|c|c|}
\hline Criterion & $\mathrm{N}$ & $M_{H}$ & $G_{T}$ \\
\hline $\mathrm{N}$ & 1 & 2 & 0,7 \\
\hline$M_{H}$ & 0,5 & 1 & 0,9 \\
\hline$G_{T}$ & 1,43 & 1,11 & 1 \\
\hline
\end{tabular}

Table 6: Matrix of Pairwise Comparisons $n, M_{H}, G_{T}$

Based on the matrix of pairwise comparisons, we calculate the main eigenvector, which has the following form:

$$
\left(y_{1} ; y_{2} ; y_{3}\right)^{T}=(1,12 ; 0,77 ; 1,17)^{T}
$$

To obtain the vector of priorities, we normalize the main eigenvector:

$$
\left(y_{1}^{\text {norm }} ; y_{2}^{\text {norm }} ; y_{3}^{\text {norm }}\right)^{T}=(0,37 ; 0,25 ; 0,38)^{T}
$$

After normalization, we calculate the consistency relation, which is 0.09 , which satisfies the consistency criterion for the third-order matrix, therefore, based on the vector of priorities, we can calculate the total control action.

\section{Conclusions}

On the basis of the resulting knowledge base, the test procedure for internal combustion engines has been developed according to GOST 18509-88 «Tractor and combine diesel engines. Methods of bench tests». This standard involves the measurement of motor parameters in a stationary mode with a step equal to $200 \mathrm{rpm}$. Fuel consumption is chosen as low as possible, which allows for an economical mode of operation, and the torque in its characteristics coincides with the corresponding revolutions.

\section{Acknowledgements}

The work is performed according to the Russian Government Program of Competitive Growth of Kazan Federal University.

\section{References}

[1] L. Guihang, W. Jian, W. Qiang, S. Jingui, "Application for diesel engine in fault diagnose based on fuzzy neural network and information fusion," 2011 IEEE 3rd International Conference on Communication Software and Networks, ICCSN 2011, art. no. 6014398, pp. 102 - 105, 2011.

[2] M. Shah, V. Gaikwad, S. Lokhande, S. Borhade, "Fault identification for I.C. engines using artificial neural network," Proceedings of 2011 International Conference on Process Automation, Control and Computing, PACC 2011, art. no. 5978891, 2011.

[3] X. Li, F. Yu, H. Jin, J. Liu, Z. Li, X. Zhang, "Simulation platform design for diesel engine fault,” 2011 International Conference on Electrical and Control Engineering, ICECE 2011 - Proceedings, art. no. 6057562, pp. 4963 - 4967, 2011.

[4] Lenar A. Galiullin; Rustam A. Valiev, "Internal combustion engine fault simulation method," IIOAB OURNAL, №9, pp. 91-96, 2018.

[5] L.A. Galiullin, R.A. Valiev, "Modeling of internal combustion engines test conditions based on neural network," (2016) International Journal of Pharmacy and Technology, 8 (3), pp. 14902-14910.

[6] Y. Yu, J. Yang, "The development of fault diagnosis system for diesel engine based on fuzzy logic," Proceedings - 2011 8th International Conference on Fuzzy Systems and Knowledge Discovery, FSKD 2011, 1, art. no. 6019556, pp. 472 - 475, 2011.

[7] Lenar A. Galiullin; Rustam A. Valiev, Khairullin A. Haliullovich, "Method for modeling the parameters of the internal combustion engine,” IIOAB JOURNAL, №9, pp. 83-90, 2018.

[8] Lenar A. Galiullin; Rustam A. Valiev, "Control vector for ice automated test and diagnostic system," DILEMAS CONTEMPORANEOS-EDUCACION POLITICA Y VALORES, №6 SI, article №95, 2018.

[9] L.A. Galiullin, R.A. Valiev, "An automated diagnostic system for ICE," (2018) Journal of Advanced Research in Dynamical and Control Systems, 10 (10 Special Issue), pp. 1767-1772.

[10] D. Wei, "Design of Web based expert system of electronic control engine fault diagnosis," BMEI 2011 Proceedings 2011 International Conference on Business Management and Electronic Information, 1, art. no. 5916978, pp. 482 - 485, 2011.

[11] R.A. Valiev, A.Kh. Khairullin, V.G. Shibakov, "Automated Design Systems for Manufacturing Processes," Russian Engineering Research, 35(9). pp. 662 - 665, 2015.

[12] L.A. Galiullin, R.A. Valiev, "Method for neuro-fuzzy inference system learning for ICE tests," (2018) Journal of Advanced Research in Dynamical and Control Systems, 10 (10 Special Issue), pp. 1773-1779.

[13] R. Ahmed, M. El Sayed, S.A. Gadsden, J. Tjong, S. Habibi, "Automotive internal-combustion-engine fault detection and classification using artificial neural network techniques," IEEE Transactions on Vehicular Technology, 64 (1), № 6803044, pp. 21-33, 2015.

[14] L.A. Galiullin, R.A. Valiev, “Automation of Diesel Engine Test Procedure,” IEEE 2016 2ND International Conference on Industrial Engineering, Applications And Manufacturing (ICIEAM), Published: 2016. 
[15] L.A. Galiullin, “Development of Automated Test System for Diesel Engines Based on Fuzzy Logic,” IEEE 2016 2ND International Conference on Industrial Engineering, Applications And Manufacturing (ICIEAM) Published: 2016.

[16] L.A. Galiullin, R.A. Valiev, "Modeling of internal combustion engines by adaptive network-based fuzzy inference system," (2018) Journal of Advanced Research in Dynamical and Control Systems, 10 (10 Special Issue), pp. 1759-1766.

[17] J. Chen, R. Randall, N. Feng, B. Peeters, H. Van Der Auweraer, "Automated diagnosis system for mechanical faults in IC engines," 10th International Conference on Condition Monitoring and Machinery Failure Prevention Technologies, CM 2013 and MFPT 2013, 2, pp. 892-903, 2013.

[18] N. McDowell, G. McCullough, X. Wang, U. Kruger, G.W. Irwin, "Application of auto-associative neural networks to transient fault detection in an IC engine," Proceedings of the 2007 Fall Technical Conference of the ASME Internal Combustion Engine Division, pp. 555-562, 2008.

[19] L.A. Galiullin, R.A. Valiev, "Optimization of the parameters of an internal combustion engine using a neural network," (2018) Journal of Advanced Research in Dynamical and Control Systems, 10 (10 Special Issue), pp. 1754-1758.

[20] J. Chen, R. Randall, B. Peeters, W. Desmet, H. Van Der Auweraer, "Neural network based diagnosis of mechanical faults in IC engines," Institution of Mechanical Engineers - 10th International Conference on Vibrations in Rotating Machinery, pp. 679-690., 2012.

[21] L.A. Galiullin, R.A. Valiev, "Diagnostics Technological Process Modeling for Internal Combustion Engines," 2017 International Conference on Industrial Engineering, Applications and Manufacturing (ICIEAM) Published: 2017.

[22] R.B. Randall, "The application of fault simulation to machine diagnostics and prognostics," 16th International Congress on Sound and Vibration 2009, ICSV 2009, 8, pp. 5042-5055, 2009.

[23] Lenar A. Galiullin, Rustam A. Valiev, Lejsan B. Mingaleeva, "Development of a Neuro-Fuzzy Diagnostic System Mathematical Model for Internal Combustion Engines,” HELIX, Volume: 8, Issue: 1, Pages: 2535-2540, Published: 2018.

[24] Lenar A. Galiullin, Rustam A. Valiev, "Diagnosis System of Internal Combustion Engine Development," Revista Publicando, Volume: 4, Issue: 13, Pages: PR128-PR137, Part: 2, Published: 2017.

[25] D. Danfeng, M. Yan, G. Xiurong, "Application of PNN to fault diagnosis of IC engine," 2009 2nd International Conference on Intelligent Computing Technology and Automation, ICICTA 2009, 2, № 5287738, pp. 495-498, 2009.

[26] Lenar A. Galiullin, Rustam A. Valiev, "Mathematical modelling of diesel engine testing and diagnostic regimes," Turkish Online Journal of Design Art and Communication, Volume: 7, Pages: 1864-1871, Published: DEC 2017. 